\title{
INTRATHECAL MORPHINE AS POSTOPERATIVE ANALGESIA FOR KNEE ARTHROPLASTY Retrospective study of pain control and side effects
}

\author{
Pato, $R^{1} ;$ Pedro, M.C. ${ }^{2}$
}

Central Lisbon University Hospital Center Anestesiology Director: Dra Isabel Fragata $\left({ }^{1}\right.$ Resident/trainee at $\mathrm{CHULC} ;{ }^{2}$ Graduated Assistent of Anesthesiology at CHULC)

\section{BACKGROUND:}

Intrathecal morphine (ITM) is an effective analgesia technique used in surgeries since 1979 as treatment of postoperative acute pain. Total knee arthroplasty is a common surgery in older patients with expected intense postoperative pain both in rest and in movement. ITM as proved a 12 to 24 hours period of effective analgesia, using doses between 0,0025mg and 0,2 mg (A) in orthopaedic surgery. The use of intrathecal association of two types of opioids has been questionable for its analgesic benefit or tolerance effect or as potencial increase of side effects.

The aim of this retrospective study is both to show if the association of two intrathecal opioids has an improvement of analgesia and/or increase of side effects, compared to their use alone.

\section{METHODS:}

Population sample: 60 patients Ages: $58-87$ years old ASA: II and III

Surgery: Total Knee Arthroplasty Anesthesia: Spinal Block

\section{Group A $(n=21)$}

Hyperbaric Bupivacaíne

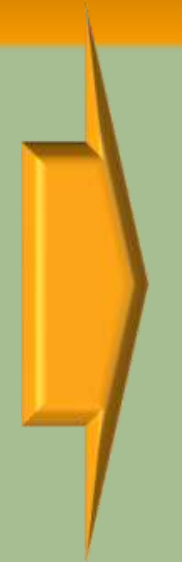

PONV prophylaxis

2 or 3 antiemetics, according to Apfel Score:

- Dexametasone 4mg

- Droperidol 0,625mg

- Ondansetron $4 \mathrm{mg}$
$0,0025 \mathrm{mg}$ Sufentanil $+$

$0,2 \mathrm{mg}$ Morphine

\section{Group B ( $n=39)$}

Hyperbaric Bupivacaíne

Vs 0,0025mg Sufentanil

All data were recorded at 24 and 48 postoperatory hours, treated with t-Student statistics analisys, using $p<0,01$.

\section{RESULTS:}

$\checkmark$ There was no significative statistic difference between the two groups in terms of pain control defined as VAS $<4$ ( $p=0,05$ for $24 \mathrm{~h}$ in rest; $p=0,13$ for $24 \mathrm{~h}$ with movement; $p=0,35$ at $48 \mathrm{~h}$ in rest and $p=0,48$ at $48 \mathrm{~h}$ in movement).

$\checkmark$ There were no statistic evidence of the increase of nausea and vomiting $(p=0,2)$, urinary retention $(p=0,3)$ and gut ileus $(p=0,11)$ associated to the administration of two intrathecal opioids. However, the data shows statistic increase of pruritus associated to the combination of Morphine and Sufentanil $(p<0,01)$.

Patients documented satisfaction superior to $75 \%$ (good and very good) for both groups.

PAIN SCORE (VAS)

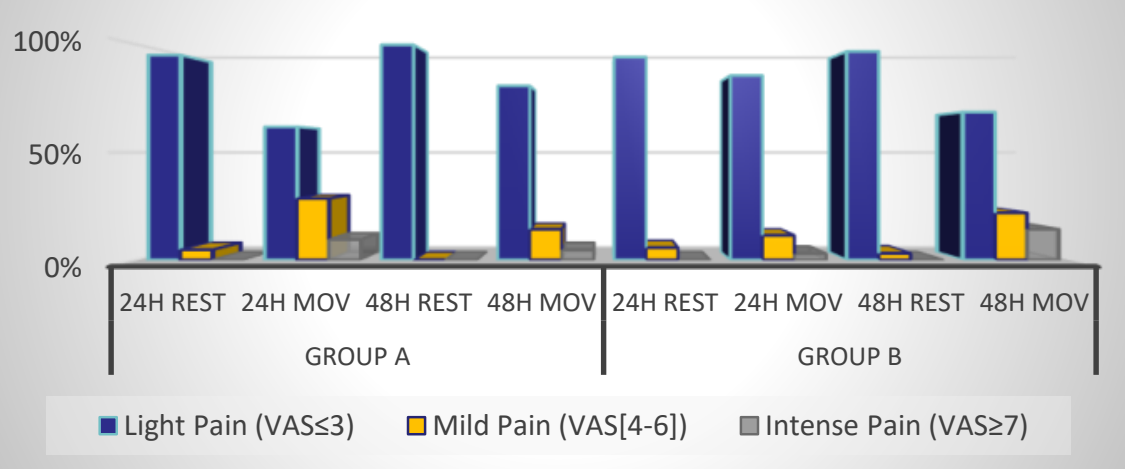

SIDE EFFECTS

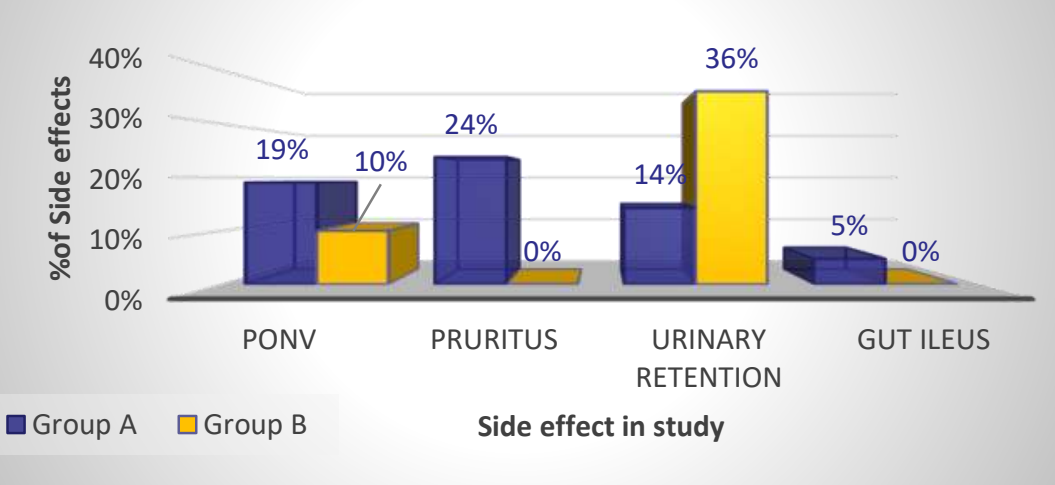

PATIENT SATISFATION

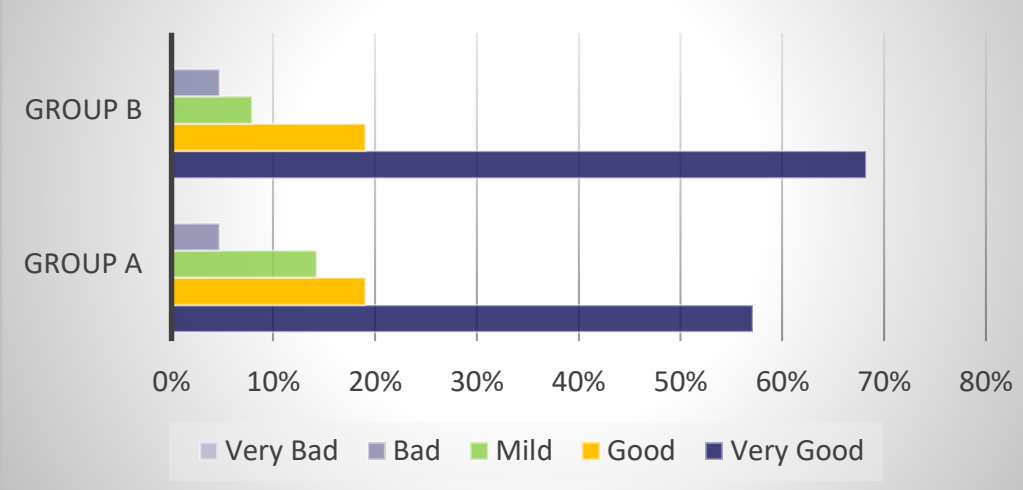

\section{CONCLUSION:}

According to our study Intrathecal Morphine $(0,2 \mathrm{mg})$ brings no benefit to the analgesic effect.

Statistical results demonstrate there is only an increase of pruritus as result of the association of the two intrathecal opioids. There were no evidence of a significant increase on the other side effects.

References: (A)Rathmell, J et al - Intrathecal Morphine for Postoperative Analgesia:A Randomized, Controlled, Dose-Ranging Study After Hip and Knee Arthroplasty, Anesth Analg 2003; (B) Frassanito, L et al - Post-operative analgesia following total knee arthroplasty: comparison of low-dose intrathecal morphine and single-shot ultrasound-guided femoral nerve block, Eur Rev Med Pharmacol Sci 2010; (C) KJIJçkaya,', R et al - Comparison of the Effects of Intrathecal Fentanyl and Intrathecal Morphine on Pain in Elective Total Knee Replacement Surgery, 